\title{
A expansão da macrometrópole e a criação de novas RMs: um novo rumo para a metropolização institucional no estado de São Paulo?
}

The expansion of the macrometropolis and the creation
of new metropolitan regions: a new trend for institutional
metropolization in the state of São Paulo?

Henrique Rezende de Castro Wilson Ribeiro dos Santos Júnior

\begin{abstract}
Resumo
0 artigo propõe fazer uma avaliação da gestão metropolitana paulista a partir da década de 2010, quando se verifica, por um lado, a regulamentação e a normatização, pelo governo estadual, de novas regiões metropolitanas e, por outro, a consolidação da macrometrópole paulista como escala regional de planejamento. As assimetrias do federalismo brasileiro, no tocante às relações intergovernamentais de caráter conflituoso e competitivo, têm sido um dos principais entraves para a consolidação da gestão metropolitana. Com a entrada em vigor, em 2015, do Estatuto da Metrópole, a nova legislação federal reforça a necessária reflexão sobre os rumos da metropolização institucional, que, no caso paulista, ainda não logrou promover a superação das persistentes desigualdades socioespaciais expressas no tecido urbano-metropolitano.
\end{abstract}

Palavras-chave: gestão metropolitana; metropolização institucional; planejamento regional; macrometrópole paulista.

\begin{abstract}
The article evaluates São Paulo's metropolitan management from 2010 onwards, in light of the state government's regulation of new metropolitan regions and the consolidation of the São Paulo macrometropolis as a regional scale of planning. The asymmetries of the Brazilian federalism concerning the conflictive and competitive character of intergovernmental relations have been one of the main obstacles to the consolidation of the metropolitan management. With the Metropolis Statute, which came into force in 2015, the new federal legislation reinforces the necessary reflection on the trends of institutional metropolization, which, in the case of São Paulo, has not yet succeeded in overcoming the persistent socio-spatial inequalities expressed in the urbanmetropolitan tissue.
\end{abstract}

Keywords: metropolitan management; institutional metropolization; regional planning; São Paulo macrometropolis. 


\section{Introdução}

0 presente trabalho propõe realizar uma avaliação crítica sobre a gestão metropolitana no estado de São Paulo, a partir da década de 2010. Destaca-se, nesse período, um impulso legal-normativo de metropolização institucional, em que se reforça um modelo de gestão altamente centralizada pelo governo paulista, cenário em que foram então criadas novas Regiões Metropolitanas (RMs) que, conjuntamente, consolidam a macrometrópole paulista como principal escala de planejamento estadual.

A macrometrópole paulista simboliza exemplarmente o fenômeno de espraiamento territorial da urbanização, como já observado em estudos anteriores (Moura, 2008), seguindo uma dinâmica de expansão da metrópole paulistana e de revalorização do espaço metropolitano pelo capital enquanto "forma urbana universal" (Castells, 1999), resultado de um movimento histórico de reestruturação produtiva internacional e da resultante da nova divisão técnica e territorial do trabalho, fenômenos comumente associados ao conceito de "globalização".

A consolidação do planejamento na escala macrometropolitana pelo governo estadual aponta para um modelo centralizador, com a concentração dos instrumentos e dos recursos estratégicos para a gestão metropolitana. A questão, porém, é que tal modelo não foi capaz de promover a cooperação interfederativa para a realização das chamadas funções públicas de interesse comum. Dentre os problemas enfrentados, encontram-se questões cruciais que envolvem, de forma estrutural, o federalismo assimétrico no Brasil, com rebatimento direto sobre as relações intergovernamentais, e a dificuldade de vincular financiamentos específicos para a execução de políticas públicas na escala metropolitana, a qual comumente demanda vultuosos investimentos, principalmente em termos de infraestrutura (sistema de trens e de metrô, por exemplo).

0 artigo está dividido em três seções. Na primeira é traçada a evolução do quadro normativo-legal sobre gestão metropolitana no estado de São Paulo no período pós-Constituição de 1988 até a década de 2010. Na segunda, são tecidos comentários a respeito da emergência da escala macrometropolitana no planejamento estadual paulista. Na terceira, avaliam-se o conteúdo normativo e algumas referências acadêmicas críticas sobre o Estatuto da Metrópole, lei federal aprovada em 2015. Por fim, são feitas algumas considerações sobre o rumo da metropolização institucional no estado de São Paulo.

\section{Trajetória da metropolização institucional em São Paulo}

Primeiramente, cabe expor a definição de gestão metropolitana utilizada neste trabalho. Trata-se de uma forma de gestão pública em que, por meio de processos de ordem legal e normativa, promovem-se a institucionalização e a estruturação de campos funcionais específicos dentro do poder público estadual para operar, de forma integrada com os municípios, o planejamento e a gestão das funções públicas de interesse comum dentro de um mesmo território funcional. A partir dessa perspectiva, 
[...] a expressão Gestão Metropolitana emerge como termo agregador da necessidade de planejar e buscar soluções para as questões sociais e econômicas decorrentes dessa justaposição de lógicas territoriais individuais. (Spink, Teixeira e Clemente, 2009, p. 455)

A dimensão da governança metropolitana, entendida como um modelo de gestão ampliada, com a participação ativa de atores não públicos, não se aplica ao contexto em análise, que está mais centrado na gestão exercida pelo ator governamental, tido como principal agente nos processos de planejamento e execução de políticas públicas de caráter metropolitano.

Expõe-se descritivamente, a seguir, a trajetória normativa-legal da gestão metropolitana em São Paulo, ${ }^{1}$ cujo resgate é importante para se compreenderem as bases do novo marco regulatório instituído a partir de 2011.

A Constituição Federal de 1988 delegou, aos estados federados, a competência para instituir regiões metropolitanas para realizar as chamadas funções públicas de interesse comum. ${ }^{2}$ A forma como se daria a gestão metropolitana, tanto nas RMs existentes quanto nas que seriam futuramente criadas, ficou ao livre-arbítrio de cada estado, uma vez que não houve regulação constitucional dessa matéria (tarefa que só recentemente se procurou resgatar com o advento do Estatuto da Metrópole).

As principais referências normativas legais para a gestão metropolitana no estado de São Paulo estão nos artigos de $n^{\circ}$ s $153^{\circ}$ ao $158^{\circ}$ da Constituição Estadual de 1989 e na lei complementar estadual $n^{\circ} 760$, de $1^{\circ}$ de agosto de 1994. Na carta estadual, a gestão prevista para as RMs prevê a criação de um conselho, de caráter normativo e deliberativo, que deverá integrar a entidade pública de caráter territorial, ${ }^{3}$ que é responsável pelo planejamento, direção e execução das funções públicas de interesse comum. Já a referida lei complementar estabelece as características para um território se configurar como região metropolitana; a obrigação de o governo estadual emitir parecer aprovando a criação de RM, segundo os critérios devidos; e a necessidade de haver audiências públicas com os municípios envolvidos. $\mathrm{Na}$ mesma lei complementar foram ainda elencados os campos funcionais que correspondem às funções públicas de interesse comum e, por fim, mas não menos importante, foram designadas a composição e o funcionamento do Conselho de Desenvolvimento ${ }^{4}$ que cada RM deve criar, seguindo a especificação dada pela Constituição Estadual de 1989.

Conforme aponta Hotz (2000, pp. 95-96), depois da experiência de implantação da RM da Baixada Santista, em 1996, foi possível, ao governo estadual, aprimorar as futuras proposições, o que se observou na criação da RM de Campinas, pela lei complementar $n^{\circ} 870$, de 2000. Pela primeira vez, em uma normatização relativa à gestão metropolitana, foi prevista a criação de um conselho consultivo, formado por representantes dos legislativos estadual e municipal e também da sociedade civil. Incluiu-se, assim, ao menos legalmente, a participação popular, algo já previsto desde 1989 na Constituição Estadual e que, na lei complementar de 1994, somente constava de forma marginal (limitada a direito à voz em reunião do Conselho de Desenvolvimento, a ter acesso a documentos e a pedir audiência pública, sem que nada disso garantisse participação ativa no planejamento e na gestão metropolitana). 
Para visualizar a trajetória nas normas jurídicas aqui discutidas e que compõem a base legal da gestão metropolitana em São Paulo, o Quadro 1 transcreve o número, a data e o conteúdo principal de cada norma editada, começando pela criação da RM de São Paulo, ainda durante o regime militar, na década de 1970 (cuja estrutura só viria a ser reorganizada a partir de 2011, como será visto mais adiante).
Sobre as leis complementares que criaram as RMs da Baixada Santista e a de Campinas, além do destacado sobre a inovação da previsão de constituição de Conselho Consultivo, é importante anotar que a constituição das entidades públicas de caráter territorial, aspecto crucial para a gestão metropolitana, teve sua feição construída paulatinamente por meio de decretos que foram regulamentando a criação das referidas RMs. Ou seja, a prática

Quadro 1 - Principais normas jurídicas de âmbito federal e do estado de São Paulo acerca da questão metropolitana, até o ano de 2000

\begin{tabular}{|c|c|c|}
\hline Norma Jurídica & Data & Conteúdo \\
\hline Lei Federal Complementar n.14 & $\begin{array}{l}8 \text { de junho } \\
\text { de } 1973\end{array}$ & $\begin{array}{l}\text { Estabelece as regiões metropolitanas de São Paulo, Belo Horizonte, } \\
\text { Porto Alegre, Recife, Salvador, Curitiba, Belém e Fortaleza. }\end{array}$ \\
\hline $\begin{array}{l}\text { Constituição da República Federativa } \\
\text { do Brasil de } 1988\end{array}$ & $\begin{array}{l}5 \text { de outubro } \\
\text { de } 1988\end{array}$ & $\begin{array}{l}\text { Capítulo III - Dos Estados Federados; art. } 25^{\circ}, \S 3^{\circ} \text { : } \\
\text { "Os Estados poderão, mediante lei complementar, instituir regiões } \\
\text { metropolitanas, aglomerações urbanas e microrregiões, constituídas } \\
\text { por agrupamentos de municípios limítrofes, para integrar a } \\
\text { organização, o planejamento e a execução de funções públicas de } \\
\text { interesse comum". }\end{array}$ \\
\hline Constituição Estadual de São Paulo & $\begin{array}{l}5 \text { de outubro } \\
\text { de } 1989\end{array}$ & $\begin{array}{l}\text { Capítulo II - Da Organização Regional; Seção I Dos Objetivos, Diretrizes } \\
\text { e Prioridades; Art. } 152^{\circ} \text {. Seção II Das Entidades Regionais; Art. } 153^{\circ} \text { a } \\
158^{\circ} \text {. }\end{array}$ \\
\hline Lei Complementar Estadual n. 760 & $\begin{array}{l}1^{\circ} \text { de agosto } \\
\text { de } 1994\end{array}$ & $\begin{array}{l}\text { Estabelece diretrizes para a Organização Regional do Estado de São } \\
\text { Paulo. }\end{array}$ \\
\hline Lei Complementar Estadual n. 815 & $\begin{array}{l}30 \text { de julho } \\
\text { de } 1996\end{array}$ & $\begin{array}{l}\text { Cria a Região Metropolitana da Baixada Santista e autoriza o Poder } \\
\text { Executivo a instituir o Conselho de Desenvolvimento da Região } \\
\text { Metropolitana da Baixada Santista, a criar entidade autárquica e a } \\
\text { constituir o Fundo de Desenvolvimento Metropolitano da Baixada } \\
\text { Santista, e dá providências correlatas. }\end{array}$ \\
\hline Lei Complementar Estadual n. 870 & $\begin{array}{l}19 \text { de junho } \\
\text { de } 2000\end{array}$ & $\begin{array}{l}\text { Cria a Região Metropolitana de Campinas, o Conselho de } \\
\text { Desenvolvimento da Região Metropolitana de Campinas e autoriza o } \\
\text { Poder Executivo a instituir entidade autárquica, a constituir o Fundo } \\
\text { de Desenvolvimento Metropolitano da Região de Campinas, e dá } \\
\text { providências correlatas. }\end{array}$ \\
\hline
\end{tabular}

Elaborado pelos autores.

Fontes: Assembleia Legislativa do Estado de São Paulo e Subchefia para Assuntos Jurídicos da Casa Civil da Presidência da República. 
da gestão em si foi se materializando aos poucos e ao longo do tempo, o que construiu uma trajetória de aprendizagem institucional importante que serviu de legado para o novo ímpeto institucional relativo ao tema metropolitano, na década de 2010 (ver Quadro 2). Tal caminho marcou também outro aspecto fundamental, que é a centralidade do papel do governo estadual no planejamento e na regulamentação da matéria, indicando a prioridade, ao menos no âmbito legal, conferida à questão metropolitana na perspectiva de organização regional do território estadual.

Houve intensa movimentação normativa-legal acerca da gestão metropolitana a partir de 2011, com a criação da Secretaria de Desenvolvimento Metropolitano (SDM). Mesmo sendo desativada dois anos depois, com a justificativa, na época, de contenção de gastos da máquina estadual diante da crise econômica,

\section{Quadro 2 - Legislação federal e estadual paulista sobre normas relativas à criação e organização institucional das RMs, no período pós-2010}

\begin{tabular}{|c|c|c|}
\hline Norma Jurídica & Data & Conteúdo \\
\hline Decreto Estadual n. 56.639 & $\begin{array}{l}1^{\circ} \text { de janeiro } \\
\text { de } 2011\end{array}$ & $\begin{array}{l}\text { Organiza a Secretaria de Desenvolvimento Metropolitano e dá providências } \\
\text { correlatas. }\end{array}$ \\
\hline Decreto Estadual n. 56.887 & $\begin{array}{l}30 \text { de março } \\
\text { de } 2011\end{array}$ & $\begin{array}{l}\text { Institui o Sistema Estadual de Desenvolvimento Metropolitano, cria a Câmara } \\
\text { de Desenvolvimento Metropolitano e dá providências correlatas. }\end{array}$ \\
\hline $\begin{array}{l}\text { Lei Complementar Estadual } \\
\text { n. } 1.139\end{array}$ & $\begin{array}{l}16 \text { de junho } \\
\text { de } 2011\end{array}$ & $\begin{array}{l}\text { Reorganiza a Região Metropolitana da Grande São Paulo, cria o respectivo } \\
\text { Conselho de Desenvolvimento e dá providências correlatas. }\end{array}$ \\
\hline $\begin{array}{l}\text { Lei Complementar Estadual } \\
\text { n. } 1.166\end{array}$ & $\begin{array}{l}9 \text { de janeiro } \\
\text { de } 2012\end{array}$ & $\begin{array}{l}\text { Cria a Região Metropolitana do Vale do Paraíba e Litoral Norte e dá } \\
\text { providências correlatas. }\end{array}$ \\
\hline Decreto Estadual n. 58.107 & $\begin{array}{l}5 \text { de junho } \\
\text { de } 2012\end{array}$ & $\begin{array}{l}\text { Institui a Estratégia para o Desenvolvimento Sustentável do Estado de São } \\
\text { Paulo } 2020 \text { e dá providências correlatas. }\end{array}$ \\
\hline Decreto Estadual n. 59.866 & $\begin{array}{l}2 \text { de dezembro } \\
\text { de } 2013\end{array}$ & $\begin{array}{l}\text { Dispõe sobre a desativação da Secretaria de Desenvolvimento Metropolitano } \\
\text { e dá providências correlatas. }\end{array}$ \\
\hline $\begin{array}{l}\text { Lei Complementar Estadual } \\
\text { n. } 1.241\end{array}$ & $\begin{array}{l}8 \text { de maio } \\
\text { de } 2014\end{array}$ & Cria a Região Metropolitana de Sorocaba e dá providências correlatas. \\
\hline Decreto Estadual n. 61.038 & $\begin{array}{l}1^{\circ} \text { de janeiro } \\
\text { de } 2015\end{array}$ & $\begin{array}{l}\text { Organiza a Casa Civil, do Gabinete do Governador, e dá providências } \\
\text { correlatas (funções e estrutura da Subsecretaria de Assuntos Metropolitanos). }\end{array}$ \\
\hline Lei Federal n. 13.089 & $\begin{array}{l}12 \text { de janeiro } \\
\text { de } 2015\end{array}$ & $\begin{array}{l}\text { Institui o Estatuto da Metrópole, altera a lei n. 10.257, de } 10 \text { de julho de } \\
2001 \text { (Estatuto da Cidade), e dá outras providências. }\end{array}$ \\
\hline $\begin{array}{l}\text { Lei Complementar Estadual } \\
\text { n. } 1.290\end{array}$ & $\begin{array}{l}6 \text { de julho } \\
\text { de } 2016\end{array}$ & Cria a Região Metropolitana de Ribeirão Preto e dá providências correlatas. \\
\hline
\end{tabular}

Elaboração pelos autores.

Fontes: Assembleia Legislativa do Estado de São Paulo e Subchefia para Assuntos Jurídicos da Casa Civil da Presidência da República. 
o tema não foi deixado de lado, uma vez que, ao ser transferida para o "guarda-chuva" da Casa Civil do gabinete do governador - renomeada como Subsecretaria de Assuntos Metropolitanos (SAM) -, essa estrutura ficou igualmente responsável pela condução centralizada do Sistema Estadual de Desenvolvimento Metropolitano e da Câmara de Desenvolvimento Metropolitano, diretamente ligados ao poder executivo na figura do governador.

Voltando a 2011, verifica-se, pelas datas de promulgação dos decretos, que a primeira atividade desenvolvida foi a de promover, enfim, a reorganização da RM de São Paulo, que desde a década de 1970, e mesmo após a normatização vista na seção anterior, ainda não tinha sido feita. Após o estabelecimento das RMs da Baixada Santista (1996) e de Campinas (2000), o processo de institucionalização metropolitana só foi retomado em 2011, quando novas propostas de RMs então foram feitas se baseando no aprendizado institucional acumulado da gestão implementada anteriormente.

Foram criadas, em um espaço de cinco anos após a instituição do sistema, a RM do

Figura 1 - Mapa das regiões metropolitanas, aglomerações urbanas e unidade regional localizadas, criadas até 2016 no estado de São Paulo, com as respectivas áreas urbanizadas

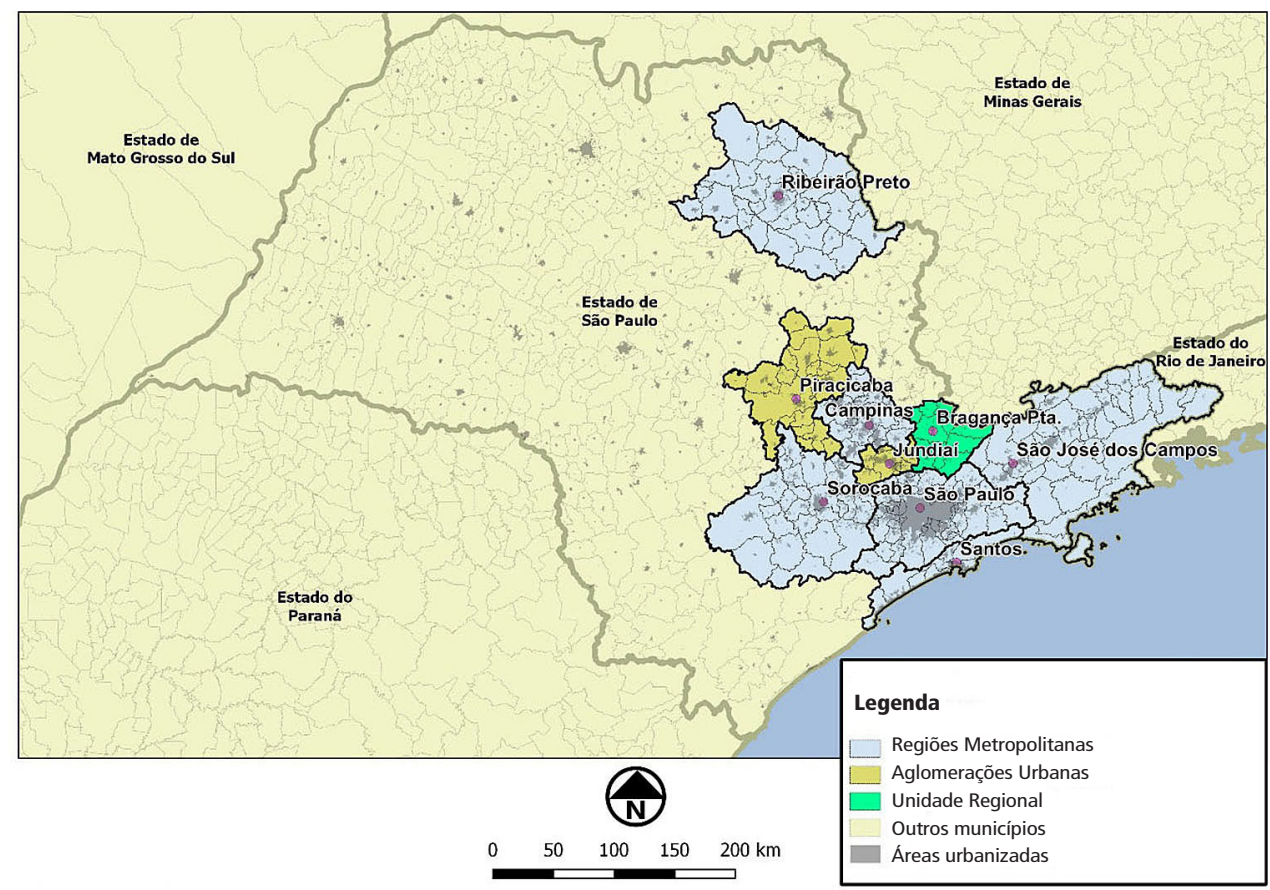

Fonte: elaborado pelos autores, com informações da Emplasa.

Nota: "aglomerações urbanas" e "unidade regional" são designações cuja significação atende a critérios utilizados pela Emplasa e embasados em legislação estadual. 
Vale do Paraíba e Litoral Norte (nucleada por São José dos (ampos), a de Sorocaba e, a mais recente, a de Ribeirão Preto, todas contando com o mesmo modelo de gestão consolidado a partir do modelo normativo-legal da década precedente ${ }^{5}$ (ver Figura 1). A organização regional do território paulista passa a ter, nas RMs e na macrometrópole, as principais unidades territoriais de planejamento - propostas, negociadas e implementadas diretamente pelo governo estadual.

Ainda sobre o novo quadro legal acima delineado, nota-se que as RMs paulistas, com exceção da RM de Ribeirão Preto, foram criadas antes da instituição no novo marco federal relativo à gestão metropolitana. 0 Estatuto da Metrópole, promulgado em 2015, estabelece novas diretrizes e, inclusive, prazos para se realizarem adequações da gestão das RMs existentes em todo o País. Tal fato introduz uma série de fatores importantes para análise e compreensão da nova dinâmica de institucionalização metropolitana em São Paulo, principalmente no que diz respeito à adequação ao novo marco normativo federal.

Com o objetivo de traçar algumas características complementares sobre o conjunto metropolitano paulista, além da trajetória institucional descrita acima, finaliza-se esta seção com uma descrição quantitativa da dimensão populacional e da riqueza do conjunto das RMs institucionalizadas em São Paulo, apontando os dados, todos relativos ao ano de 2010 , sobre a população residente, o Produto Interno Bruto (PIB) e o PIB per capita para cada RM, para o total do estado de São Paulo e para o Brasil (ver Tabela 1). Cabe notar que, no ano de coleta dos dados, só existiam instituídas legalmente as RMs de São Paulo, Baixada Santista e Campinas.

Tabela 1 - População, PIB, PIB per capita para as regiões metropolitanas de São Paulo, estado de São Paulo e Brasil, ano-referência 2010

\begin{tabular}{l|c|c|c}
\hline Região Metropolitana, UF e Brasil & População $2010^{\text {[a] }}$ & $\begin{array}{c}\text { PIB 2010 } \\
\text { a preços correntes }_{(1000 ~ R \$)^{[\text {[b] }}}\end{array}$ & $\begin{array}{c}\text { PIB per capita 2010 } \\
\text { (R\$) }^{[\text {[b] }}\end{array}$ \\
\hline RM São Paulo & 19.683 .975 & $701.848 .590,74$ & $35.655,84$ \\
RM Baixada Santista & 1.664 .136 & $47.302 .457,75$ & $28.424,63$ \\
RM Campinas & 2.808 .906 & $98.814 .101,16$ & $35.178,86$ \\
RM Vale do Paraíba e Litoral Norte & 2.264 .594 & $61.698 .187,89$ & $27.244,70$ \\
RM Sorocaba & 1.726 .785 & $42.950 .560,69$ & $24.873,14$ \\
RM Ribeirão Preto & 1.511 .140 & $37.182 .963,59$ & $24.605,90$ \\
Estado de São Paulo & 41.262 .199 & $1.247 .595 .926,61$ & $30.243,17$ \\
Brasil & 190.755 .799 & $3.770 .084 .871,58$ & $19.766,33$ \\
\hline
\end{tabular}

Elaborado pelos autores.

Fontes: [a] Censo Demográfico de 2010 e Instituto Brasileiro de Geografia e Estatística - IBGE; [b] Fundação Sistema Estadual de Análise de Dados - Seade. ${ }^{6}$ 
A partir das informações levantadas, tendo como referência o ano de 2010, pode-se fazer algumas anotações relevantes para retratar alguns pontos concernentes à dinâmica demográfica e econômica das RMs paulistas:

- Do conjunto metropolitano, a RM de São Paulo destacava-se por concentrar $47,7 \%$ da população paulista e por responder por $56,3 \%$ do PIB estadual e $18,6 \%$ do Brasil, apresentando também o maior PIB per capita entre as RMs consideradas.

- As RMs paulistas juntas totalizavam 71,9\% da população do estado e 15,5\% da brasileira. Respondiam por $79,3 \%$ do PIB estadual e por $26,3 \%$ do PIB brasileiro.

- O PIB per capita tomado em separado de cada RM, e mesmo do estado de São Paulo, demonstra o nível de concentração de riqueza gerada por esses recortes territoriais ante 0 valor apresentado do PIB per capita brasileiro.

- Os maiores PIB per capita foram registrados nas RMs de São Paulo e de Campinas, enquanto os menores, nas RMs de Sorocaba e Ribeirão Preto.

0 desafio de gestão desse espaço singular do território brasileiro - a maior extensão de ocupação urbana contínua e geradora de grande parte da riqueza do País - encontra-se em como promover o desenvolvimento, por meio do arranjo institucional metropolitano, que na prática não goza de autonomia enquanto um ente governamental singular.

A metrópole não é uma unidade política, não tem prerrogativas político-institucionais de uma unidade federativa, mas existe como espaço fundamental na dinâmica econômica na medida em que é o desenvolvimento das metrópoles que puxa a economia brasileira. (Clementino e Almeida, 2015, p. 212)
É preciso, ainda, problematizar o papel da gestão metropolitana nesse cenário, dada sua complexidade em termos socioespaciais. Apesar de concentrar riquezas, é notório que os territórios metropolitanos também apresentam problemas urbanos graves. Aprovar leis de criação de RMs e estabelecer regulamentação normativo-legal por si sós, portanto, não garantiriam a efetividade da organização regional. Como questiona Silva Neto (2010),

A integração dos entes públicos está ocorrendo? A regionalização político-administrativa e, consequentemente, a gestão metropolitana, está a serviço do interesse comum ou se presta à viabilização de projetos hegemônicos ocultos pelo discurso da regionalização? A organização regional do Estado está conseguindo reduzir desigualdades socioespaciais históricas? Há, de fato, uma política territorial no Brasil?

Sem querer ir tão longe nas indagações acima referidas pelo autor, que merecem reflexão mais detida e profunda, resta questionar se, mesmo com toda estrutura formal concretizada no nível legal, por parte do governo de São Paulo, haveria na prática uma gestão promotora de políticas públicas metropolitanas que estivessem "a serviço do bem comum" e que reduzissem as desigualdades socioespaciais?

Alcançar tal objetivo, no entanto, não é tarefa fácil, pois

Existem várias razões para explicar a dificuldade de se criarem políticas públicas metropolitanas. Por exemplo, a dificuldade em estabelecer uma ação cooperada em situação de rivalidade política entre municípios ou mesmo entre municípios e o governo estadual; as diferenças econômicas e demográficas 
entre os municípios que integram a Região Metropolitana, a constante mudança de legislação específica no âmbito estadual, a falta de um órgão gestor que consiga reunir horizontalmente os diversos interesses entre os municípios, além do clássico problema orçamentário originado pela ausência de um fundo mais substantivo de financiamento das políticas metropolitanas e também pela incapacidade financeira dos municípios ante os diversos problemas que os mesmos já enfrentam isoladamente. (Spink, Teixeira e Clemente, 2009, p. 468)

Como pode ser observado na passagem acima, não são poucos os problemas a serem enfrentados. Larga produção acadêmica já se debruçou sobre o assunto, e há uma convergência em indicar, fundamentalmente, o problema originário do federalismo assimétrico e competitivo vigente no Brasil (cf. Oliveira, 2012; Pinto, 2009; Denaldi e Klink, 2010). Há de se destacar também as análises internacionais sobre gestão metropolitana, que apontam, dentre outros problemas, para a dificuldade de se promover a ação coletiva dos atores envolvidos na composição das estruturas dos arranjos metropolitanos, tanto em países federados quanto nos unitários (cf. Lefèvre, 1998; 2015). Ou seja, e voltando ao objeto em foco, não seria possível apenas descrever o modelo de gestão metropolitana adotado no caso paulista sem levantar essas importantes indagações e problematizações que fazem parte de um contexto estruturante mais amplo e que também influem diretamente sobre o planejamento para a macrometrópole paulista.

\section{Consolidação da macrometrópole paulista no planejamento estadual}

Além do marco legal instituído pelo governo do estado de São Paulo, em que se constata a maior ênfase normativa e institucional sobre a questão metropolitana, também destaca-se a emergência da macrometrópole paulista, uma proposição administrativa considerada como plataforma de integração de políticas públicas e ações articuladas para um território que compreende, além das RMs de São Paulo, Baixada Santista, Campinas, Sorocaba e Vale do Paraíba e Litoral Norte, também as aglomerações urbanas de Jundiaí e Piracicaba e a unidade regional de Bragança Paulista (ver Figura 2).

MMP [Macrometrópole Paulista] é exemplo claro dessa nova escala de metropolização, que compreende o espaço territorial formado pelas regiões metropolitanas e aglomerações urbanas do estado de São Paulo e por um conjunto de centros urbanos médios, que tendem a ampliar e intensificar a conurbação entre seus territórios, bem como o seu grau de articulação e integração funcional, com elevada influência do seu polo principal: o município de São Paulo. Nesse território, coexistem diferentes morfologias urbanas, compondo uma rede de cidades com elevado nível de integração funcional, e interagem metrópoles de caráter mundial, nacional e regional, aglomerações urbanas e centros urbanos com significativos papéis de centros regionais. (Negreiros, Santos e Miranda, 2015, p. 127) 
Figura 2 - Mapa da macrometrópole paulista, com as regiões metropolitanas, aglomerações urbanas e unidade regional que a compõem, bem como da área urbanizada

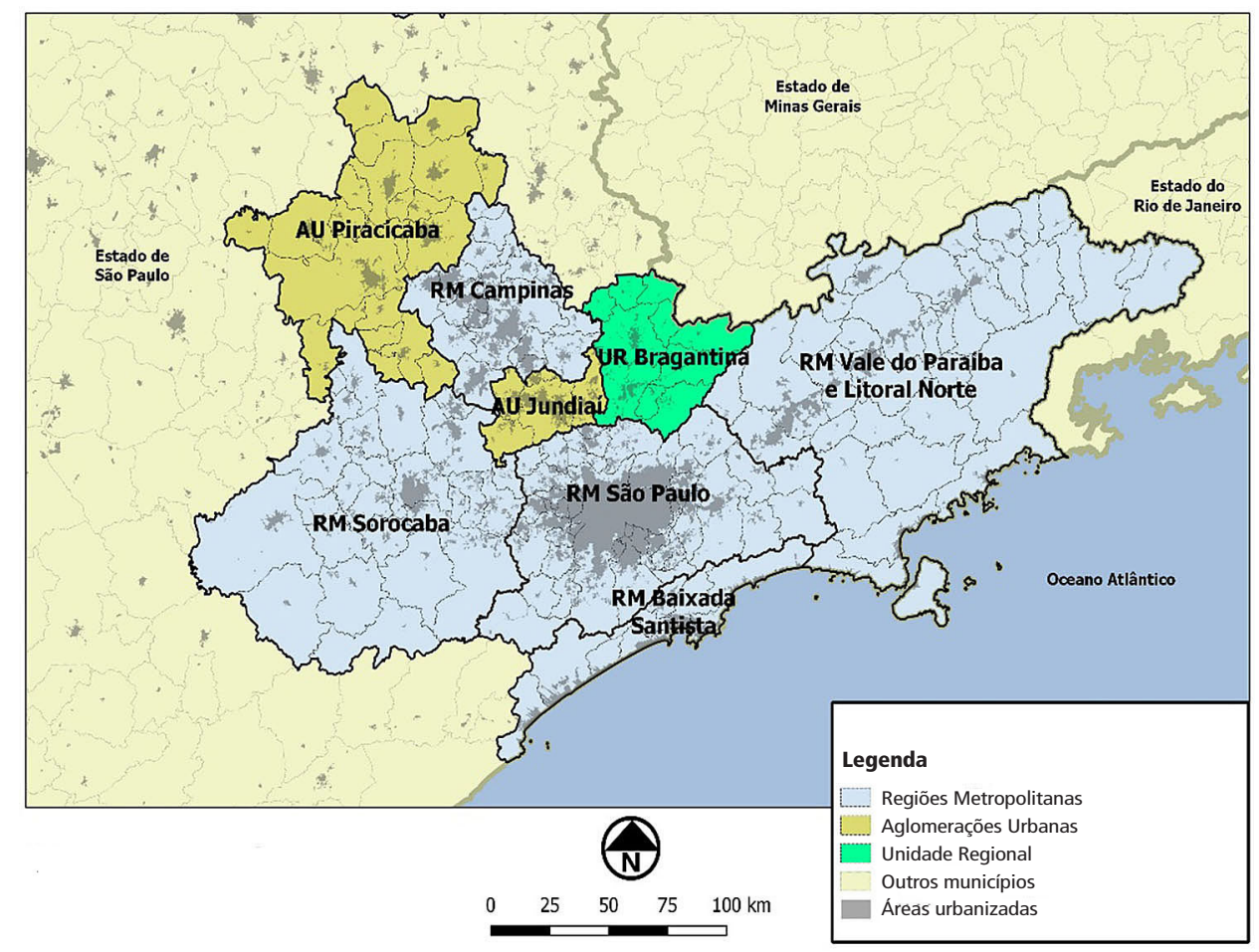

Fonte: elaborado pelos autores, com informações da Emplasa.

0 termo macrometrópole paulista foi adotado pela Empresa Paulista de Planejamento Metropolitano S/A - Emplasa, ${ }^{8}$ que então passa a utilizar tal designação nos planos oficialmente lançados a partir da instituição do Sistema Estadual de Desenvolvimento Metropolitano, em 2011. No fim do mesmo ano, entra em cena o "PAM - Plano de Ação da Macrometrópole 2013-2040" (Emplasa, 2013), documento que basicamente instrui a ação pública para o desenvolvimento regional, identificando potencialidades, mas também tendo em conta os entraves existentes, em um reconhecimento de que a gestão metropolitana até então não estaria plenamente estabelecida. ${ }^{9} 0$ termo volta a ser empregado na "Estratégia para o Desenvolvimento Sustentável do Estado de São Paulo 2020" (São Paulo, 2012), documento lançado em 2012, no qual consta a gestão metropolitana como central no planejamento para o desenvolvimento da macrometrópole paulista. Posterior produção oficial de relatórios e livros sobre o assunto, por parte da Emplasa, demonstra claramente a consolidação da nova escala no planejamento estadual, como também pode ser confirmado pela inclusão dos projetos previstos no PAM no Plano Plurianual 2016-2019 do governo estadual. ${ }^{10}$ 
Sobre a origem dessa nova escala, a macrometrópole paulista, cabe dizer que

[...] Sua conformação está associada ao avanço da urbanização, da interiorização do desenvolvimento econômico e da desconcentração produtiva e populacional da RMSP, processos dos quais se desdobrou a configuração de um território marcado por significativa heterogeneidade estrutural, que acumula condições e potencialidades de desenvolvimento socioeconômico diferenciadas do restante do país e concentra, igualmente, expressiva dívida social, na forma de existência de precárias condições de moradia, de ocupação de áreas de risco, de carência de infraestruturas urbanas e sociais, etc. (Davanzo et al., 2011, p. 104)

Conforme apontado pelas autoras, e também reconhecido pela própria Emplasa, oportunidades e desafios são a tônica do planejamento dessa nova estrutura territorial, que tem na gestão metropolitana uma ferramenta ainda a ser lapidada, de forma a dar conta dos encargos que lhe estão destinados nos planos e na regulamentação estadual paulista.

Aprofundar os estudos sobre o alcance do PAM, os impactos que gerarão sobre a atuação governamental e sobre a regionalização das políticas públicas, considerando também as avaliações sobre o alcance de suas propostas, são tarefas para futuros trabalhos. No presente artigo, procurou-se destacar a importância e especificidade da nova escala de planejamento adotada em São Paulo, assim como sua necessária adaptabilidade ao novo marco regulatório federal, proporcionado pelo advento do Estatuto da Metrópole, como será visto a seguir.

\section{Impactos do Estatuto da Metrópole sobre a gestão metropolitana}

Após longa tramitação legislativa no Congresso Nacional, em que se passaram onze anos entre a proposta original, de 2004, e a instituição da lei complementar, em 2015, o Estatuto da Metrópole (lei federal n. 13.089, de 12 de janeiro de 2015) impôs nova regulamentação normativa-legal no trato da questão metropolitana, estipulando diretrizes e lançando mão de novos instrumentos para o planejamento, a gestão e a execução das funções públicas de interesse comum. Resumidamente, o Estatuto da Metrópole aborda:

- A observância das normas gerais do direito urbanístico, expressas no Estatuto da Cidade (lei federal n. 10.257, de 10 de julho de 2001) e por demais leis federais e políticas territoriais de âmbito nacional.

- Um glossário dos principais termos tratados na lei, com definições (mesmo que genéricas) sobre o que é metrópole, RM, aglomeração urbana, função pública de interesse comum, gestão plena, plano de desenvolvimento urbano integrado e governança interfederativa.

- Critérios mínimos que condicionam a criação de uma RM por leis complementares estaduais.

- Adoção de uma forma específica de gestão - a governança interfederativa -, cujo escopo procura viabilizar a necessária cooperação entre os entes federados envolvidos, assim como possibilitar um maior nível de participação da sociedade, indicando, inclusive, a estrutura básica mínima a ser adotada. 
- A criação de instrumentos específicos, como o Plano de Desenvolvimento Urbano Integrado (PDUI), as operações urbanas consorciadas, as parcerias público-privadas interfederativas, etc.

- A compatibilização dos Planos Diretores dos municípios ao PDUI, cujas diretrizes estão expressas no corpo da lei (macrozoneamento, parcelamento, uso e ocupação do solo urbano, etc.).

- 0 disciplinamento do apoio da União ao desenvolvimento urbano integrado, via obrigatoriedade da adoção da gestão plena (estrutura básica com governança interfederativa ativa e PDUI aprovado) para então as RMs e aglomerações urbanas ficarem aptas a receber apoio técnico e orçamentário do governo federal.

- A criação do Sistema Nacional de Desenvolvimento Urbano - SNDU, coordenado pela União e com a participação dos estados e municípios, que contará com um subsistema de planejamento e informações metropolitanas.

- A previsão de incorrer em improbidade administrativa o governador ou agente público que atue na governança interfederativa e que não garanta, nos prazos exigidos, a aprovação do PDUI, que se torna peça obrigatória para todas as RMs e as aglomerações urbanas (incluindo as já criadas antes do advento do Estatuto da Metrópole).

Havia ainda, no processo de tramitação do projeto de lei, a previsão da criação de um Fundo Nacional de Desenvolvimento Urbano Integrado, mas os artigos referentes a esse item foram todos vetados pelo gabinete da Presidência da República que, diante da imposição de restrições orçamentárias em tempos de crise, preferiu não "cristalizar recursos", ou seja, diminuir a fatia manejável para se garantir objetivos macroeconômicos, como a certeza do superávit primário. Crise que também afeta diretamente estados e municípios, tornando a questão sobre o financiamento das políticas públicas metropolitanas mais delicado e potencialmente conflituoso, dadas as discrepâncias entre capacidade de investimento e a distribuição do ônus do financiamento das ações metropolitanas entre os municípios (Ribeiro, 2015).

Em uma das avaliações acadêmicas que se seguiram à instituição do Estatuto da Metrópole, Moura e Hoshino (2015) sugerem que a lei foi o resultado politicamente possível, ante os descompassos do pacto federativo, tendo por aspectos positivos ter aberto o diálogo sobre o desenvolvimento regional e ter dado um passo importante ao disciplinar a institucionalização e a governança de unidades territoriais urbanas nos estados. Entretanto, o desafio federalista permanece.

0 pacto federativo brasileiro e a forma como vêm se estabelecendo as articulações entre os atores políticos - o Estado, o mercado e a sociedade civil - têm representado limites à constituição de sistemas de gestão metropolitana e gerado impasses à cooperação intermunicipal, acarretando conflitos de governança. (Lacerda e Ribeiro, 2014, p. 185)

Ainda sobre o Estatuto, Compans (2015) aponta, dentre outros problemas, a questão da indefinição sobre o conteúdo do que seriam as funções públicas de interesse comum (a lei somente diz que se trata de políticas públicas que extrapolam a competência municipal). Além disso, a autora assinala o controverso problema relativo à regulamentação do uso do solo urbano, que também teria ficado indefinida, trazendo inconsistências que podem mesmo levar a uma ingovernabilidade metropolitana. 
Tendo em vista a problemática acima exposta, qualquer análise sobre os desdobramentos do Estatuto da Metrópole deve levar em consideração os limites impostos pela realidade das relações intergovernamentais no Brasil, marcadas por assimetrias de poder e pela dinâmica cooperativa/competitiva entre a União, os estados e os municípios (Ismael, 2014). Como tornar governável um território permeado por uma estrutura de relações federativas historicamente conflitiva, considerando, especialmente, entre outros fatores, o reforço da autonomia municipal consagrado pela Constituição de 1988? Como fazer cooperar atores públicos e privados, firmando um compromisso em torno da governança metropolitana interfederativa? Estes são apenas alguns dos desafios que se fazem presentes para o gestor público e que fazem parte relevante da agenda de pesquisa acadêmica sobre essa temática.

Voltando à gestão metropolitana no estado de São Paulo, cabe identificar quais os impactos gerados pelo advento do Estatuto da Metrópole. De imediato vale lembrar que a lei federal previu prazos para adequação, o que impõe uma agenda de ação aos agentes públicos envolvidos, uma vez que estão previstas sanções pela não realização de parâmetros estabelecidos. Foram verificadas, junto à Emplasa, as referências de adequação do planejamento existente para as novas regras da lei federal. Primeiramente, em termos de noticiário, pode ser identificada a movimentação desse órgão público em torno de encontros e palestras promovidos sobre o Estatuto da Metrópole, ${ }^{11}$ assim como uma referência ao adiantado processo de adequação relativo à RM da Baixada Santista. ${ }^{12}$ Ou seja, tendo em conta a obrigatoriedade de adequação das
RMs existentes ao novo marco legal vir acompanhada igualmente da possibilidade de sanções, caso não haja a adequação prevista, a Emplasa imediatamente se mobilizou em torno das novas diretrizes, promovendo encontros e palestras com especialistas e, assim, abrindo caminho às ações necessárias para adequação ao Estatuto da Metrópole.

No caso do estado São Paulo, considerando que desde a década de 1990 já havia se estabelecido ao longo dos anos um modelo de gestão metropolitana prevendo uma estrutura muito próxima do que foi estipulado pelo Estatuto da Metrópole, inclusive com a realização de planos integrados em que, com relação ao PDUI exigido pelo Estatuto, a diferença é basicamente a nomenclatura (cf., por exemplo, o Plano Metropolitano de Desenvolvimento Estratégico da Baixada Santista, de 2014), bastando acertar os detalhes exigidos pela nova lei. É de se destacar o fato de a RM da Baixada Santista e a de Campinas terem servido como espécie de "laboratório" das práticas de planejamento e gestão metropolitanos, cujo acúmulo de experiências possibilitou o aprimoramento da regulação e, por conseguinte, uma suposta facilidade de se readequar aos novos parâmetros federais. 0 impacto sobre 0 planejamento da macrometrópole paulista, no aspecto normativo, seria apenas o de promover a adequação necessária. Na prática, porém, os entraves à gestão metropolitana permanecem, dificultando que os objetivos traçados por planos como o PAM sejam alcançados.

0 caso paulista (assim como dos demais estados que têm RMs instituídas) possui outros desafios para além da readequação regulatória do marco normativo-legal. Como visto acerca das críticas ao Estatuto da Metrópole, é 
perceptível que problemas estruturais da própria forma de organização e distribuição de poder territorial do País trazem entraves que também precisam ser enfrentados, posto que se torna ociosa uma estrutura institucional montada no plano legal sem ser funcional no plano prático, ou seja, que não consiga promover as sinergias necessárias entre os diferentes entes federados para a consolidação da gestão metropolitana.

O Estatuto da Metrópole avançou nas formas jurídico-normativas de tratar o território para além das três esferas de governo na federação trina brasileira. Falta, contudo, avançar na pactuação federativa no sentido de conferir estímulos significativos ao desenvolvimento de comportamentos cooperativos. (Santos e Vasques, 2015, pp. 1787-1788)

0 estado de São Paulo hoje conta com seis regiões metropolitanas (cinco delas compondo a macrometrópole) e duas aglomerações urbanas, concentrando um dos maiores contingentes populacionais e também parcela significativa da riqueza produzida no País. Da mesma dimensão, são os problemas a serem enfrentados, tais como o déficit habitacional, estresse hídrico e abastecimento de água, mobilidade urbana, etc. 0 planejamento e a gestão metropolitana, a partir do Estatuto da Metrópole e de seus instrumentos, promoverão a redução das desigualdades socioespaciais e a melhoria da qualidade de vida da população metropolitana? Até que ponto os entraves oriundos das assimetrias federativas e dos conflitos nas relações intergovernamentais impedirão os avanços necessários à superação dos problemas apontados?

\section{Considerações finais}

0 artigo se propôs a descrever o quadro normativo-legal sobre a gestão metropolitana no estado de São Paulo, passando pelos diferentes períodos de sua evolução, mas com especial atenção ao novo momento da "virada metropolitana", identificada a partir de 2011 com a nova legislação estadual em vigor. Destacou também a emergência da escala macrometropolitana no planejamento e a proposição de planos pelo governo estadual paulista. Por fim, avaliou a nova legislação federal imposta em 2015 e os impactos correlatos sobre a gestão metropolitana. As seções assim trabalhadas permitiram trazer elementos importantes para a reflexão sobre o rumo da metropolização institucional paulista.

O levantamento bibliográfico utilizado na pesquisa possibilitou suscitar questões pertinentes a problemas e entraves enfrentados para a consolidação da gestão metropolitana, em grande parte relacionados com as assimetrias do federalismo brasileiro e com as consequentes relações intergovernamentais conflituosas. Tais obstáculos parecem estar presentes no caso analisado, em que concorre diretamente, como fator causal, o modelo centralizador da gestão exercido pelo governo do Estado de São Paulo, em particular no planejamento da macrometrópole paulista.

A produção e o debate acadêmico sobre a questão metropolitana, tanto no plano nacional quanto internacional, encontraram novo ímpeto em tempos recentes, considerando a influência dos macroprocessos 
ligados à globalização e à reestruturação produtiva e os impactos sobre os territórios metropolitanos. Ao avaliar a produção acadêmica recente, percebe-se que, após o Estatuto da Metrópole, houve um novo impulso na produção de trabalhos sobre a temática, proporcionando vasto material de pesquisa, tanto teórico quanto metodológico, avançando na reflexão em torno de questões-chave, como por exemplo a gestão e a governança das regiões metropolitanas.

Entretanto, verifica-se a continuidade das desigualdades socioespaciais nas RMs, em especial dos países em desenvolvimento. Os territórios metropolitanos são marcados por um intenso processo de valorização do capital, expresso na financeirização do mercado imobiliário, que por sua vez retroalimenta a dinâmica perversa de exclusão, por meio de fenômenos como o da propagação da gentrificação em centros urbanos com intensa atividade fundiária especulativa. A gestão de políticas públicas de caráter metropolitano está longe de proporcionar as respostas necessárias para ao menos amenizar essa dinâmica perversa, muito em função, inclusive, do próprio esvaziamento que as estruturas institucionais acabam sofrendo, em virtude de problemas relacionados a legitimidade política e conflito de competências, dentre outros fatores.

0 processo de metropolização institucional no caso paulista, conforme aqui analisado, ainda está longe de promover os mecanismos necessários para a superação das desigualdades socioespaciais que persistem em esgarçar o tecido social nas grandes aglomerações urbanas, como a de São Paulo. 0 plano legal-normativo metropolitano, de acordo com o que foi aprovado, está deslocado do plano real-prático da vida cotidiana e do próprio histórico de planejamento e execução de políticas públicas de caráter metropolitano do governo paulista, que sempre exerceu grande poder centralizador e de tutela sobre as políticas territoriais sobre seu território estadual, sem, no entanto, promover a sinergia necessária para a ação cooperada entre diferentes atores, tanto públicos como privados, com diferentes graus de autonomia e poder de intervir na agenda pública. 0 resultado é a perpetuação de problemas sem respostas nas regiões metropolitanas, agravando situações de precariedade no acesso aos direitos básicos, como habitação e saneamento, configurando, assim, a falta de uma gestão metropolitana efetiva como um grave fator de injustiça social.

\section{Henrique Rezende de Castro}

Pontifícia Universidade Católica de Campinas, Programa de Pós-Graduação em Urbanismo. Campinas, SP/Brasil.

hrdecastro@gmail.com

\section{Wilson Ribeiro dos Santos Júnior}

Pontifícia Universidade Católica de Campinas, Programa de Pós-Graduação em Urbanismo. Campinas, SP/Brasil.

wilson@puc-campinas.edu.br 


\section{Notas}

(1) O recorte contempla somente as regiões metropolitanas. Não será abordado neste trabalho, portanto, a gestão relativa às aglomerações urbanas de Jundiaí (criada em 2011) e a de Piracicaba (2012).

(2) Conforme o artigo $25^{\circ}$, § 3: "Os Estados poderão, mediante lei complementar, instituir regiões metropolitanas, aglomerações urbanas e microrregiões, constituídas por agrupamentos de municípios limítrofes, para integrar a organização, o planejamento e a execução de funções públicas de interesse comum".

(3) Entidades que posteriormente serão identificadas como Agências Metropolitanas, às quais os conselhos ficarão subordinados.

(4) O Conselho de Desenvolvimento é formado pelos representantes indicados pelo executivo estadual e pelos executivos municipais, sendo, na letra da lei, garantida a paridade na representação, de forma que as decisões por votação respeitem a proporção de $50 \%$ da participação entre Estado e municípios.

(5) Resumidamente, tal legado se constituiu na forma de gestão baseada na composição do conselho de caráter normativo e deliberativo (formado pelos representantes do executivo estadual e dos municípios), do conselho consultivo (composto por representantes dos legislativos estadual e municipais, assim como da sociedade civil), de um fundo metropolitano e, subordinando todas essas estruturas, a entidade pública de caráter territorial, conhecida em São Paulo como Agência Metropolitana, responsável por direção, planejamento e execução das políticas públicas de caráter metropolitano (seguindo os setores funcionais identificados enquanto funções públicas de interesse comum).

(6) O Seade é uma fundação vinculada à Secretaria de Planejamento e Gestão do Estado de São Paulo.

(7) Somente a unidade regional de Bragança Paulista ainda não possui normatização legal própria para estrutura de gestão, apesar do reconhecimento enquanto recorte territorial pertencente à macrometrópole paulista.

(8) Tal como a Subsecretaria de Assuntos Metropolitanos, a Emplasa é vinculada à Casa Civil do governo paulista. Tem por objetivo promover o planejamento regional e metropolitano do estado de São Paulo.

(9) A falta de consenso político, a desarticulação dos setores governamentais, a falta de transparência pública nos processos e mesmo a ineficiência da ação pública metropolitana são alguns dos problemas identificados pela Emplasa nos processos relativos à gestão metropolitana em São Paulo.

(10) "Projetos do PAM são incorporados no Plano Plurianual do governo estadual”, notícia veiculada no portal online da Emplasa. Disponível em: <https://www.emplasa.sp.gov.br/Comunicacao/ Releases/Release/Projetos-do-PAM-sao-incorporados-no-Plano-Plurianual-do-governoestadual-1>. Acesso em: 5 set 2016. 
(11) Dentre as notícias, podemos destacar: “Advogados debatem Estatuto da Metrópole e PDUI com participação da Emplasa”, disponível em: <https://www.emplasa.sp.gov.br/Comunicacao/ Nalmprensa/Imprensa/Advogados-debatem-Estatuto-da-Metropole-e-PDUI-com-participacaoda-Emplasa-1>. Acesso em: 5 set 2016; "Emplasa participa de encontro em Brasília sobre Estatuto da Metrópole", disponível em: <https://www.emplasa.sp.gov.br/Comunicacao/ Releases/Release/Emplasa-participa-de-encontro-em-Brasilia-sobre-Estatuto-da-Metropole>. Acesso em: 5 set 2016; e "Debatedores apontam desafios para atender exigências do Estatuto da Metrópole". Disponível em: https://www.emplasa.sp.gov.br/Comunicacao/Nalmprensa/ Imprensa/Debatedores-apontam-desafios-para-atender-exigencias-do-Estatuto-daMetropole>. Acesso em: 5 set 2016.

(12) "Baixada Santista já está $80 \%$ adequada ao estatuto da metrópole". Disponível em: <https:// www.emplasa.sp.gov.br/Comunicacao/Releases/Release/Baixada-Santista-ja-esta-80adequada-ao-estatuto-da-metropole>. Acesso em: 5 set 2016.

\section{Referências}

CASTELLS, M. (1999). A Sociedade em Rede. São Paulo, Paz e Terra.

CLEMENTINO, M. do L. M. e ALMEIDA, L. de S. B. (2015). Construção técnico-política da governança metropolitana. Cadernos Metrópole. São Paulo, v. 17, n. 33, pp. 201-224.

COMPANS, R. (2015). Metropolitan ungovernability. Revista Brasileira de Estudos Urbanos e Regionais, v. 17, n. 2, pp. 11-24.

DAVANZO, A. M. Q.; PIRES, M. C. S.; NEGREIROS, R. e SANTOS, S. M. M. dos (2011). "Metropolização e rede urbana". In: PEREIRA, R. H. M. e FURTADO, B. A. (orgs.). Dinâmica urbano-regional: rede urbana e suas interfaces. Brasília, Ipea.

DENALDI, R. e KLINK, J. J. (2010). “Reestruturação produtiva, governanças competitivas e a fragmentação socioespacial do território metropolitano: revisitando o caso de Curitiba”. In: KLINK, J. J. (org.). Governança das Metrópoles. Conceitos, experiências e perspectivas. São Paulo, Annablume.

EMPLASA - Empresa Metropolitana de Planejamento da Grande São Paulo S.A. (2013). Plano de Ação da Macrometrópole Paulista 2013/2040. São Paulo, Emplasa.

HOTZ, E. F. (2000). A organização metropolitana pós-constituição de 1988. São Paulo em Perspectiva, v. 14, n. 4, pp. 91-98.

ISMAEL, R. (2014). "A trajetória do federalismo na redemocratização brasileira: competição como regra e cooperação como princípio”. In: D’ARAUJO, M. C. (org.). Redemocratização e Mudança Social no Brasil. Rio de Janeiro, Editora FGV.

LACERDA, N. e RIBEIRO, S. (2014). Limites da gestão metropolitana e à governança cooperada intermunicipal no Brasil. Revista Eure. Santiago, v. 40, n. 121, pp. 185-202.

LEFÈVRE, C. (1998). Metropolitan government and governance in western countries: a critical review. International Journal of Urban and Regional Research, v. 22, n. 1, pp. 9-25. 
LEFÈVRE, C. (2015). “Las experiencias internacionales de cooperación metropolitana: una visión de los mecanismos de governanza en los países desarrollados". In: PUGLIESE, L. (org.). Políticas e instituciones metropolitanas. Buenos Aires, Ministerio del Interior y Transporte.

MOURA, R. (2008). Arranjos urbano-regionais: uma categoria complexa na metropolização brasileira. Revista Brasileira de Estudos Urbanos e Regionais, v. 10, n. 2, pp. 29-49.

MOURA, R. e HOSHINO, T. de A. P. (2015). Estatuto da Metrópole: enfim, aprovado! Mas o que oferece à metropolização brasileira? Observatório das Metrópoles, Artigos Semanais, 29 jan 2015, Rio de Janeiro, pp. 1-15. Disponível em: http://www.observatoriodasmetropoles.net/download/ estatuto_metropole_artigo_rosa.pdf. Acesso em: 17 mar 2015.

NEGREIROS, R.; SANTOS, S. M. M. dos e MIRANDA, Z. A. I. de (2015). Nova escala de planejamento, investimento e governança na macrometrópole paulista. Revista Iberoamericana de Urbanismo, ano 7, n. 12 , pp. 121-135.

OLIVEIRA, R. V. de (2012). Federalismo assimétrico brasileiro. Belo Horizonte, Arraes.

PINTO, S. G. B. (2009). Regiões Metropolitanas: por que não cooperam? Rio de Janeiro, Letra Capital.

RIBEIRO, T. (2015). Regiões metropolitanas como instrumento de garantia do direito à cidade nos territórios marginalizados dos aglomerados urbanos. Revista de Direito da Cidade, v. 7, n. 4.

SANTOS, A. M. S. P. e VASQUES, P. H. R. P. (2015). Política urbana no contexto federativo brasileiro - um avanço normativo na gestão dos aglomerados urbanos. Revista de Direto da Cidade, v. 7, n. 4, pp. 1771-1790.

SÃO PAULO, Estado de. Decreto no 58.107, de 5 de junho de 2012. Institui a Estratégia para o Desenvolvimento Sustentável do Estado de São Paulo 2020, e dá providências correlatas. Diário Oficial, São Paulo, SP, 6 jun. 2012. Seção 1, p. 1.

SILVA NETO, M. L. da (2010). Evolução e tendências da gestão metropolitana em São Paulo. Aspectos normativos (parte 1). Arquitextos, São Paulo, ano 11, n. 124.02, Vitruvius. Disponível em: http:// www.vitruvius.com.br/revistas/read/arquitextos/11.124/3584. Acesso em: 23 jul 2016.

SPINK, P. K.; TEIXEIRA, M. A. C. e CLEMENTE, R. (2009). Governança, governo ou gestão - o caminho das ações metropolitanas. Cadernos Metrópole. São Paulo, v. 11, n. 22, pp. 453-476.

Texto recebido em 21/mar/2017

Texto aprovado em 16/jun/2017 